\title{
EXPERIMENTAL ANALYSIS OF RADIATORS' THERMAL OUTPUT FOR HEAT ACCOUNTING
}

\author{
by
Renzo MARCHESI ${ }^{a}$, Fabio RINALDI ${ }^{a}$, Claudio TARINI ${ }^{a}$, Fausto ARPINO ${ }^{b}$, Gino CORTELLESSA ${ }^{b^{*}}$, Marco DELL'ISOLA ${ }^{b}$, Giorgio FICCO ${ }^{a}$ \\ a Department of Energy, Politecnico University of Milan, Milano, Italy \\ ${ }^{b}$ Department of Civil and Mechanical Engineering (DICeM), \\ University of Cassino and Southern Lazio, Cassino, Italy \\ Original scientific paper \\ https://doi.org/10.2298/TSCI170301168M
}

\begin{abstract}
Radiators represent the most spread heating body (installed since late 1800s) and in the last decades different radiators typologies have been proposed on the market, characterized by different materials, sizes, shapes, etc. Recent EU Directive on energy efficiency has set the obligation to install individual meters for space heating in building served by a central heating source. To this aim, when direct heat meters are not technically feasible, indirect systems like heat cost allocators are applied on each radiator in a dwelling and the knowledge of single radiators' thermal output is essential for an accurate and fair heat cost sharing. The EN 442:2014 describes a method for radiators' thermal output measurement whose expanded uncertainty is lower than $1 \%$ in reference laboratory conditions. However, radiators' thermal output is strongly dependent on installation and boundary conditions. Thus, to get radiators' thermal output at operating conditions "characteristic equations" are available but, unfortunately, they do not include any possible actual operating condition among which: installation position with respect to the wall and the floor, presence of grid/shelf/niche or an obstruction (e. g. caused by curtains), thermo-fluid-dynamic condition variations (inlet flow rate and temperature), and hydraulic connections. In this paper, the experimental results of thermal output measurement of different radiators typologies (cast iron, aluminum) at different installation conditions are presented, together with an analysis of the associate technical-economic effects on space heating cost sharing. Reductions of radiators' thermal output up to $15 \%$ due to hydraulic connections and between $10 \%$ and $20 \%$ due to flow-rate variations have been found. Furthermore, different installation conditions showed deviations between operating and standard radiators' thermal output between 5\% and 15\%.
\end{abstract}

Key words: radiators, heat accounting, thermal output, operating conditions

\section{Introduction}

Directive 2012/27/EU [1] on energy efficiency has set the obligation to install individual meters or indirect systems (e.g. heat cost allocators) allowing individual measurement of energy consumption for space heating in multi-apartment buildings supplied by district heating or common central source. In many cases this obligation, either due to architectural constraints and/or to plant configurations or to high costs, $e$. $g$. in existing buildings and especially in the historical ones [2], results in the installation of indirect heat allocation systems,

\footnotetext{
* Corresponding author, e-mail: g.cortellessa@unicas.it
} 
such as heat cost allocators. As well known, such devices are based on the estimation of thermal energy exchanged by single radiators and to this aim, the knowledge of radiator's heat output is crucial.

In recent times, radiators, in addition to their own main functionality, have also assumed a major architectural/esthetical value, which has led to the spreading of different radiators types (each characterized by different material, size, shape, etc.). Unfortunately, only rarely the actual thermal output of installed radiators is consistent with the nominal one, which is measured in the laboratory at rated temperature and at standard installation conditions. Besides, radiators are generally installed employing connections, flow rates, positions etc. that may be different from reference standard so determining thermo-fluid-dynamic conditions very different from testing. In order to investigate issues related to indirect heat accounting, it is necessary to consider the heat transfer phenomena involved, the combined radiative-convective effects and, to a negligible extent (unless in case of wrong installation), conduction. Furthermore, actual heat transfer influences the effective temperature distribution on the radiator's surface. Natural convection plays a significant role and represents from $50 \%$ to $90 \%$ of the overall thermal output depending on the radiator's type. Radiators' thermal output in operating conditions depends on several factors (average external surface temperature; shape, material, size and surface finish; water-flow rate etc.) and its knowledge is crucial for effective heating plants sizing and fair heat cost allocation [3]. Radiators are classified as a function of construction material (steel, cast iron, aluminum) and shape (i.e. panel, columns, etc.) [4, 5]. The methodology for the determination of radiators' thermal output has been achieved in the last years moving from a manufacturer's statements at the beginning of sixties, to a standard measurement in the seventies, to the recent accurate and rigorous European harmonized standards EN 442-1 [6] and EN 442-2 [7]. Moreover, some of existing heating plants are very old and accurate information about radiators' thermal output is not available or confusing and this can affect the accuracy and fairness of space heating costs sharing required by the EU Directive on energy efficiency [1]. To face this problem, different empirical solutions are adopted, in different countries. The Italian Thermo-Technical Committee (CTI) proposed that for indirect heat accounting, the thermal output must be determined in accordance to the following hierarchy: Level 1 - according to EN 442 (available since 1997), Level 2 - for heating appliances installed before the entering into force of EN 442, according to available national standards, and Level 3 - for very old plants, if Levels 1 and 2 are not applicable, thermal output should be determined through non-experimental methods if validated, such as the dimensional method described by UNI 10200 [8]. Obviously, not-experimental methods are not as accurate as the EN 442 reference method and do not give any possibility of taking in account the dependence of calculated thermal output on installation conditions and actual operating parameters (i. e. water-flow rate).

Looking at the scientific literature, only few works are available about the measurement of radiators' thermal output at operating conditions. Brady et al. [9] investigated the onfield effects of decorated covers on radiators finding thermal output reductions up to $40 \%$ in the case of wooden cover. A CFD simulation was performed by Embaye [10] with pulsed flow using frequency ranging from $0.0083 \mathrm{~Hz}$ to $0.033 \mathrm{~Hz}$ and amplitude from $0.0168 \mathrm{~kg} / \mathrm{s}$ to $0.0228 \mathrm{~kg} / \mathrm{s}$. The results of the analysis showed that $25 \%$ improvement in the specific radiator's heat output is achievable while maintaining the same radiator target surface temperature of $50{ }^{\circ} \mathrm{C}$. Calisir et al. [11] investigated panel radiator heat output under actual operating conditions. They found radiator's heat output is most linearly increasing with increasing inlet temperature at different connection positions. Furthermore, for lower mass-flow rates higher 
temperature differences can be obtained although, due to higher mass-flow rates, higher heat outputs are observed in general.

In this paper, the authors present the results of an experimental investigation aimed at the determination of deviation of the radiators' thermal output at operating conditions from reference standard one, that is used for programming indirect heat accounting systems. Such deviation should be useful to predict the effects on the accuracy of heat accounting when indirect systems are adopted and it has not been yet fully investigated in scientific literature. In particular, the following operating conditions have been analyzed: presence of a grid, a shelf, niche, an obstruction (e.g. caused by curtains on the radiator). Installation position with respect to the wall and floor and thermal output variation employing different connections to the plant and different flow rates. In fact, for the first time, the influence of connection types, flow rates, installation conditions, temperature difference (between the heat transfer fluid and the surrounding air) on the radiators' thermal output in operating conditions has been investigated in terms of deviation from the reference standard ones.

Thermal output of different radiators has been determined experimentally in the reference conditions at the Laboratorio di Misure Ricerche Termotecniche (MRT) of the Politecnico of Milano and in operating conditions at the Laboratorio di Misure Industriali (LaMI) of Università di Cassino e del Lazio Meridionale.

\section{Thermal output of radiators}

The knowledge of radiator's thermal output in standard conditions is essential for space heating costs sharing using indirect systems, e. g. heat cost allocators conforming EN 834 [12].

For radiators installed after sixties the thermal output value is generally available, determined in compliance with national standard, while for radiators installed after 1997 such value should be determined in conformity with the European standard EN 442 [6, 7]. Unfortunately, for heaters installed in the early sixties it is hard to find standard thermal output values and for this reason different empirical procedures are adopted, which in some cases are not made known. In this scenario, the dimensional method described by UNI 10200 [11] is the empirical method adopted in the Italian market to allow the traceability of the heating costs accounting for radiators installed in the early sixties.

\section{The standard method EN 442}

The EN $442[6,7]$ allows the thermal output measurement with an uncertainty lower than $\pm 1 \%$. The boundary conditions are imposed by means of a closed and unventilated test room characterized by five water cooled walls and one not cooled. The radiator under test is exposed to the not cooled wall. All the walls are insulated, so that in this way the thermal testing conditions are independent from the external environment. The standard thermal output, $\phi$, of the radiator under test is obtained at a temperature difference $\Delta T=50^{\circ} \mathrm{C}$, while heat cost allocators require $\Delta T=60{ }^{\circ} \mathrm{C}$. In this condition is also determined the standard flow rate. The characteristic equation of the tested radiator is obtained by regression of the measured data and is given:

$$
\phi=K_{m} \Delta T^{n}
$$

where $K_{m}\left[\mathrm{WK}^{-1}\right]$ is the constant of the radiator and $n$ is the exponent of the characteristic equation, generally ranging from 1.1 to 1.4 , depending on the ratio between the thermal out- 
put exchanged by radiation and by convection. Since radiators are often made up of a number of identical vertical sections (elements or modules), the thermal output of a single element or section is given by:

$$
\phi_{L}=\frac{\Phi}{N_{\mathrm{el}}}
$$

where $\phi_{L}\left[\mathrm{WK}^{-1}\right]$ is the thermal output of a single module and $N_{\mathrm{el}}$ - the number of elements. In the case the radiators cannot be split, a module corresponds to a radiator having a conventional length of $1 \mathrm{~m}$.

The EN442 standard introduces the concept of family of radiators to take into account the size variability of radiators characterized by similar design and construction, made of identical material and presenting the same position of primary fluid connections. In order to reduce the number of models under test, EN442 also introduces the concept of type of radiators, that is a group of radiators of similar design whose cross-section remains unchanged while the height or length can vary (or which present the variation of only one characteristic dimension of the heating surface). In accordance with EN 442, the thermal output of radiators of the same type can be obtained from following equation:

$$
\phi=K_{T} L^{a} H^{b} q_{m}^{c} \Delta T^{\left(c_{0}+c_{1} H\right)}
$$

where $K_{T}\left[\mathrm{Jm}^{-2} \mathrm{~kg}^{-1} \mathrm{~K}^{-1}\right]$ is the constant of the type, $a, b, c, c_{0}$, and $c_{1}-$ the characteristic constants of the radiator, $q_{m}\left[\mathrm{kgs}^{-1}\right]-$ is the water-flow rate, $H[\mathrm{~m}]-$ the height, $L[\mathrm{~m}]-$ the length, and $\Delta T=T_{m}-T_{a}[\mathrm{~K}]$ - the difference between the average temperature of the radiator and the temperature of the test environment. The minimum number of models to be tested within a type is determined by the range of heights $H_{r}=H_{\max }-H_{\min }[\mathrm{m}]$. When the range of heights is lower or equal to $1 \mathrm{~m}$, the minimum number of models to be tested is equal to 3 . Otherwise, when $H_{r}>1 \mathrm{~m}$, the minimum number of models to be tested is four.

In order to reduce testing costs, taking into account the technical experience gained in the last forty years $[13,14]$, some simplifications have been accepted at the European standards level. In particular: for radiators constituted by elements, a direct proportionality is accepted between the element number and the thermal output, and thermal output is assumed independent from water-flow rate.

In case of radiators constituted by modules (typically made of steel or presenting a tubular shape) the EN442 requires to test up to four models for both the minimum and the maximum length. For each height the thermal output is then obtained by linear interpolation the test results. The thermal output dependence on the flow rate can also be tested by the laboratory on the request of the manufacturer. For a radiator type, assuming a constant width and a neglecting dependence of thermal output on the flow rate, the thermal output is almost linear with length and is obtained in the following simplified form:

$$
\phi=K_{T} H^{b} \Delta T^{(c 0+c 1 H)}
$$

Such approximation has been validated and accepted since it provides results lower than $2 \%$ compared to the measured ones [15]. For each radiator type and model the manufacturers must declare at least the standard thermal output value $\phi_{L}$ of a single module and its characteristic equation. 
Nevertheless, it is desirable that in modern plants the following characteristic equation should be employed for minimum and maximum length:

$$
\phi=K_{T} H^{b} q_{m}^{c} \Delta T^{(c 0+c 1 H)}
$$

that allows to properly take into account the influence of water-flow rate, $q_{m}$, on radiator's thermal output and, consequently, space heating cost sharing. Unfortunately, very often eq. (5) is not available and the variation of water-flow rate is not properly taken into account for heat cost allocation.

\section{Dimensional method UNI 10200}

For radiators installed in sixties, the dimensional method is mentioned in the Italian standard UNI 10200 [11] and allows to obtain, through an empirical calculation, the thermal output. Such method is applicable only for radiators with simple structure such as plates or sectional radiators. On the other hand, the method is not valid for convectors, fan coils, radiant panels or other systems based on the forced convection principle. The thermal output $\phi_{\Delta T 60}$, referred to a $60{ }^{\circ} \mathrm{C}$ difference between the average temperature of the radiator and the ambient, is obtained from the following relation:

$$
\phi_{\Delta T 60}=314 S+C V
$$

where $S\left[\mathrm{~m}^{2}\right]$ is a conventional external surface of the radiator, $C\left[\mathrm{Wm}^{-3}\right]-$ a characteristic coefficient of the appliance, experimentally evaluated for some radiator types and available in the UNI 10200 as a function of the radiator type, and $V\left[\mathrm{~m}^{3}\right]$ - the radiator volume. For the calculation of the external surface, $S$, and of the volume, $V$, it is considered the radiator envelope parallelepiped of height $H$, depth $D$, and width $L$. As it is evident from eq. (6), this method does not allow to determine the flow rate influence on the thermal output and related heat cost allocation.

\section{Experimental determination of thermal output in operating conditions}

The radiator thermal output is inversely proportional to its total thermal resistance which can be expressed through the following relation:

$$
R_{T}=R_{\mathrm{i}}+R_{p}+R_{\mathrm{e}}
$$

where $R_{\mathrm{i}}\left[\mathrm{KW}^{-1}\right]$ is the internal convective/radiative resistance, $R_{p}\left[\mathrm{KW}^{-1}\right]$ - the wall conductive resistance, and $R_{\mathrm{e}}\left[\mathrm{KW}^{-1}\right]$ - is the external convective/radiative resistance. The $R_{\mathrm{e}}$ value is always higher than $R_{\mathrm{i}}$, that is considerably higher than $R_{p}$. Therefore, the thermal output, $\phi_{\mathrm{eff}}$, exchanged between the external surface of the radiator and the surrounding environment depends mainly from $R_{\mathrm{e}}$. Unfortunately, on the field, thermo-fluid-dynamic conditions can be very different from reference ones ( $e . g$. due to different flow rate, different connections, etc.) Besides, radiators may present operating temperatures that can be different from reference testing ones. Therefore, the actual thermal output should be calculated by applying the following relation:

$$
\phi_{\mathrm{eff}}=\phi F=\phi\left(F_{\Delta T} F_{\mathrm{con}} F_{q_{\mathrm{m}}} F_{\mathrm{in}} F_{v r} F_{P}\right)
$$


where $F$ (dimensionless) is the overall correction factor, given by the product of the following dimensionless correction factors:

- fluid temperature correction factor, $F_{\Delta T}$, that allows thermal output correction when the average temperature difference between heat transfer fluid and environment is different form reference testing value, $\Delta T_{\mathrm{REF}}[\mathrm{K}]$ and $F_{\Delta T}$ correction factor is given by the following equation:

$$
F_{\Delta T}=\left(\frac{T_{m}-T_{a}}{\Delta T_{\mathrm{REF}}}\right)^{n}
$$

where $T_{m}$ and $T_{a}[\mathrm{~K}]$ are the arithmetic average temperature between the inlet and outlet temperature, respectively, of the fluid which flows inside the appliance and the surrounding air temperature, measured at the center of the room at a height of $0.75 \mathrm{~m}$ from the floor,

- connections correction factor, $F_{\text {con, }}$, that allows thermal output correction when the radiator working connections are different from testing conditions (inlet section is generally located at the top of the heating appliance, while outlet section is located at the bottom),

- average heat transfer fluid-flow rate correction factor, $F_{a m}$, that allows thermal output correction when thermostatic valves or other controlling equipment are installed,

- heating appliance installation correction factor, $F_{\text {in }}$, that allows thermal output correction when installation conditions are responsible of significant deviation of thermal output form expected nominal value,

- painting correction factor, $F_{v r}$, that allows thermal output correction when the radiator is painted with a paint different from the one used during tests; in this regard the standard EN 442 takes requires two distinct tests when the same radiator model painted using matt or glossy paint,

- atmospheric pressure correction factor, $F_{p}$, that takes into account the effect of pressure variation as a function of altitude, according to the following equation:

$$
F_{p}=\frac{1}{S_{k}+\left(1-S_{k}\right)\left(\frac{p_{0}}{p}\right)^{n_{\mathrm{p}}}}
$$

where $p$ is the barometric pressure measured during the test, $p_{\mathrm{o}}=1013 \mathrm{mbar}$, while $n_{\mathrm{p}}$ and $S_{k}$ are available from EN442-2 [7]. Thermal output of different radiators has been experimentally determined in the reference conditions, according to EN 442-1 and EN 442-2, at the MRT of the Politecnico of Milano and in operating conditions at the LaMI of the Universita di Cassino e del Lazio Meridionale. In particular, MRT is a European reference laboratory for the definition of the procedures of CE mark laboratories and operates according to EN 442 [16, 17]. On the other hand, the LaMI experimental set-up has been specifically designed to test radiators in actual operating conditions and it is composed by: a domestic heat generator (with a nominal thermal power of $23.7 \mathrm{~kW}$ ), an adjustable aluminum frame allowing vertical and horizontal adjustment of the radiator with respect to the wall and the floor, an auxiliary thermoconvector (for the thermal power dissipation and stabilization), a direct heat meter, and an acquisition and data processing system. Tests were conducted on commercial radiators, selected among the most used types in the last decades and removed from an existing heating plant. 
The experimental campaign was aimed to analyze the deviation of the thermal output in operating conditions with respect to the reference testing ones $[18,19]$ and to evaluate the effects of such deviation on space heating costs sharing [2]. On field tests have been conducted on aged radiators installed by 10-15 years, while in the reference laboratory, both new and aged radiators have been investigated. The technical characteristics of investigated radiators are reported in Table 1. The tests carried out were:

- analysis of the influence of installation conditions (i. e. shelf, grid, niches, obstructions due to curtains, positioning),

- analysis of the influence of connections,

- analysis of the influence of water-flow-rate, and

- analysis of deviation between the standard thermal output and the corresponding one estimated through the dimensional method.

Table 1. Technical characteristics of the investigated radiators

\begin{tabular}{||c|c|c||}
\hline \multirow{2}{*}{} & \multicolumn{2}{|c|}{ Material } \\
\cline { 2 - 3 } & Cast iron & Aluminum \\
\hline Tipology & Large culumns & Finned \\
\hline Depth $[\mathrm{mm}]$ & 145 & 96 \\
\hline Number of elements & 9 (reduced to 6 and 3) & 9 \\
\hline Height $[\mathrm{mm}]$ & 890 & 879 \\
\hline Wheelbase $[\mathrm{mm}]$ & 800 & 800 \\
\hline Lenght $[\mathrm{mm}]$ & 60 & 80 \\
\hline Connections & - & $\mathrm{G} 1$ \\
\hline Water content $[\mathrm{L}]$ & 0.99 & 0.60 \\
\hline Weight $[\mathrm{kg}]$ & 9.27 & 2.13 \\
\hline Thermal power, $\phi_{L}[\mathrm{~W}]$ & $125.50-\Delta T 50 \mathrm{~K}$ & $184.42-\Delta T 50 \mathrm{~K}$ \\
\hline Exponent, $n$ & $161.77-\Delta T 60 \mathrm{~K}$ & $236.04-\Delta T 60 \mathrm{~K}$ \\
\hline$K_{\mathrm{m} \text { EN } 442\left[\mathrm{WK}{ }^{-1}\right]}$ & $1.28243-9$ elements & 1.3535 \\
\hline$C$ UNI $10220\left[\mathrm{Wm}{ }^{-3}\right]$ & $1.26662-6$ elements & \\
\hline
\end{tabular}

\section{Thermal output measurement uncertainty}

Radiators' thermal output in operating conditions has been measured by employing a class 3 heat meter [20]. The measurement equation for thermal output is given by the characteristic equation of heat meters:

$$
\phi=K_{m} \dot{V} \Delta T_{\text {io }}
$$

where $K_{m}\left[\mathrm{kJm}^{-3} \mathrm{~K}^{-1}\right]$ is the volume-specific heat, $\dot{V}\left[\mathrm{~m}^{3} \mathrm{~s}^{-1}\right]-$ the volumetric flow rate, and $\Delta T_{\text {io }}[\mathrm{K}]$ represent the inlet-outlet temperature difference. The uncertainty affecting measure- 
ments, $u_{\phi}$, has been determined by applying the uncertainty propagation law to measurement eq. (11), obtaining the following relation and considering $K_{m}$ as a constant:

$$
u_{\phi}=K_{m}\left(\sqrt{\left(\frac{\partial \phi}{\partial \dot{V}}\right)^{2} u_{\dot{V}}^{2}+\left(\frac{\partial \phi}{\partial \Delta T_{i o}}\right)^{2} u_{\Delta T_{\mathrm{io}}}^{2}}+\frac{\sigma}{\sqrt{N}}\right)
$$

where $u_{\dot{V}}^{2}$ and $u_{\Delta T_{\mathrm{i}}}^{2}$ are the flow rate and temperature difference standard uncertainties assumed to be equal to $2 \%$ of read value and $0.1 \mathrm{~K}$, respectively, while $\sigma / N^{-1 / 2}$ is the type A uncertainty contribution, where $\sigma$ is the standard deviation and $N$ is the number of acquisitions $[21,22]$. The value of the uncertainty is obtained referring to a coverage factor equal to 2 [23]. Uncertainty affecting EN442 measurements is equal to $1 \%$ of read value.

\section{Results and discussion}

In this paragraph the authors analyze the difference between on-field thermal output of different radiators, measured at the LaMI, with respect to the corresponding one in reference testing conditions, measured at the MRT according to EN $442[6,7]$. Experimental investigations were conducted for an aluminum and a cast iron radiator and on-field measurements were conducted in different installation and operating conditions. Besides, the dimensional method described by UNI 10200 [11] was applied to estimate radiators' thermal output in actual operating condition, demonstrating that, in absence of other information, the application of such method produced a deviation with respect to the MRT reference data of about $3.5 \%$ in the case of the aluminum radiator and of about $13.5 \%$ in the case of the cast-iron radiator. It is important to notice that the dimensional method is not able to take into account the effect of different operating conditions, nor their impact on heat cost allocation.

Results accuracy has been evidenced by comparing different sets of data deriving from on field measurements, measurement in reference testing conditions and the application of the standard UNI 10200. In addition, the estimation of the measurement uncertainties has been punctually performed.

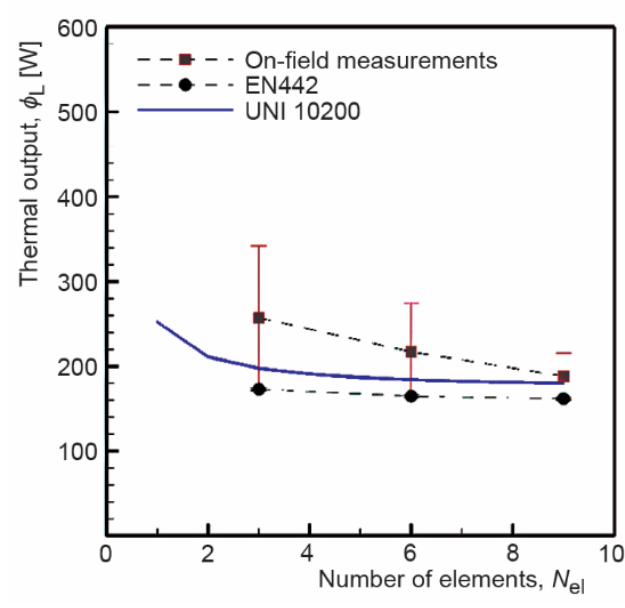

Figure 1. Thermal output per element for cast iron heating body from on field measurements, EN 442 and dimensional method (UNI 10200)

\section{Effect of the number of sections}

Figure 1 and tab. 2 show, for the cast iron radiator analyzed, the dependence of thermal output from the number of elements constituting the heating appliance. In particular, in the $y$-axis of fig. 1 the thermal output for a single element, $\phi_{L}$ is reported, obtained by dividing the total thermal output by the number of elements. Error bars in the figure represent measurement uncertainty. Radiators made up of 3, 6, and 9 elements have been experimentally analyzed. The EN 442 thermal output per element decreases from 173.0W, in the case of a 3-elements radiator, to $161.8 \mathrm{~W}$, for the 9-elements radiator, confirming that total thermal output variation with the number of elements is almost linear. Thermal output 
estimation according to UNI 10200 produces similar results, that are compatible with reference data in the analyzed range of 3-6-9 elements, but don't gives results as function of the flow rate.

Table 2. Thermal output dependence from flow rate and number of elements

\begin{tabular}{|c|c|c|c|c|c|c|c|}
\hline & & \multicolumn{3}{|c|}{ Test EN442 } & \multicolumn{3}{|c|}{ Dependence of $\phi_{C}$ from $q$} \\
\hline \multicolumn{8}{|c|}{ Test 16916 - Cast iron heating body, height $900 \mathrm{~mm}, 4$ columns, 3 elements } \\
\hline$\Delta T$ & {$[\mathrm{~K}]$} & 60.35 & 50.06 & 30.60 & 49,94 & 49.88 & 47.63 \\
\hline$q$ & {$\left[\mathrm{kgh}^{-1}\right]$} & 34.52 & 34.63 & 34.43 & 280.45 & 17.93 & 8.81 \\
\hline$\phi_{C}$ & [W] & 519.0 & 409.5 & 223.6 & 445.0 & 394.7 & 385.0 \\
\hline$\phi(50)$ & {$[\mathrm{W}]$} & - & 408.9 & - & 445.7 & 405.1 & 396.5 \\
\hline \multicolumn{8}{|c|}{ Test 16916 - Cast iron heating body, height $900 \mathrm{~mm}, 4$ columns, 6 elements } \\
\hline$\Delta T$ & {$[\mathrm{~K}]$} & 60.91 & 48.96 & 31.01 & 49.93 & 50.25 & 50.28 \\
\hline$q$ & {$\left[\mathrm{kgh}^{-1}\right]$} & 65.69 & 66.04 & 66.35 & 291.71 & 34.20 & 16.81 \\
\hline$\phi_{C}$ & [W] & 987.4 & 764.5 & 419.4 & 796.1 & 753.1 & 699.6 \\
\hline$\phi(50)$ & [W] & - & 785.2 & - & 797.5 & 748.4 & 713.7 \\
\hline \multicolumn{8}{|c|}{ Test 16916 - Cast iron heating body, height $900 \mathrm{~mm}, 4$ columns, 9 elements } \\
\hline$\Delta T$ & {$[\mathrm{~K}]$} & 61.03 & 50.27 & 31.33 & 50.25 & 49.66 & 50.15 \\
\hline$q$ & {$\left[\mathrm{kgh}^{-1}\right]$} & 99.16 & 98.61 & 99.15 & 286.45 & 49.57 & 25.06 \\
\hline$\phi_{C}$ & [W] & 1456.1 & 1134.8 & 619.1 & 1154.1 & 1084.9 & 1059.0 \\
\hline$\phi(50)$ & [W] & - & 1111.4 & - & 1154.1 & 1084.9 & 1059.0 \\
\hline
\end{tabular}

As expected, uncertainty affecting onfield measurements is much larger than uncertainty of EN 442 measurements, mainly because of a relatively low value of $\Delta T_{\mathrm{io}}$, that affects uncertainty according to eq. (10). In particular, even though on-field and EN 442 measurements are compatible, on-field measured thermal output significantly deviated from EN 442 value when the number of elements decreases and $\Delta T_{\text {io }}$ decreases accordingly. On the other hand, the two measurements are compatible for a number of elements equal to 9 .

\section{Effect of the temperature difference influence}

Figure 2 shows, for the cast iron radiator analyzed, the dependence of thermal output from temperature difference, $\Delta T$, between the

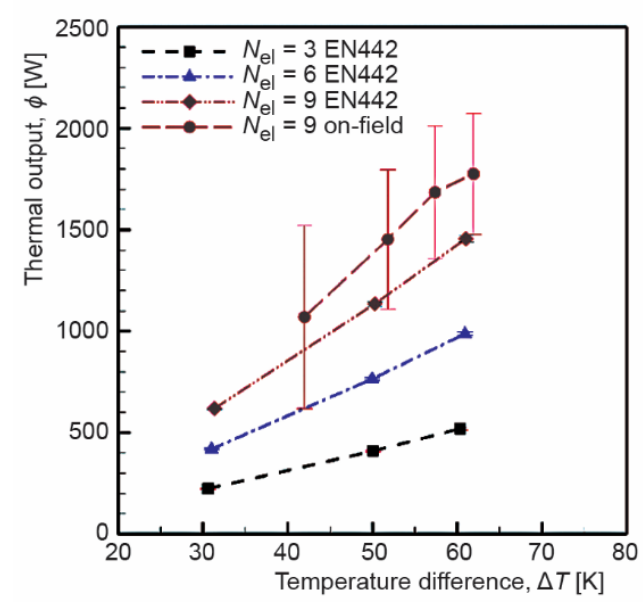

Figure 2. Thermal output as a function of temperature difference obtained for cast iron heating body from on field and EN 442 
heat transfer fluid and the surrounding air. As expected, in the considered operating temperature range the thermal output, $\phi$, is almost linearly dependent on $\Delta T$. The EN 442 measurements are available for 3,6 , and 9 elements, while the on-field measurements are only available for the 9elements case. From the analysis of Figure 2 it can be observed that on-field measurements are compatible with the EN 442 data in the whole range of $\Delta T$ considered. While the uncertainty affecting measurements at the MRT is constant and equal to $1 \%$, for the LaMI measurements uncertainty increases as the temperature difference decreases. This is due to the decrement of the thermal output when $\Delta T$ decreases, which corresponds to a reduced temperature difference of the heat transfer fluid between inlet and outlet sections. In particular, for the larger $\Delta T$ considered the heat transfer temperature drop is equal to about $\Delta T_{\mathrm{io}}=3.4^{\circ} \mathrm{C}$, which decreases to about $\Delta T_{\text {io }}=2.0^{\circ} \mathrm{C}$, for the smaller $\Delta T$ analyzed. As a consequence, measurement uncertainty affecting the thermal output, $\phi$, increases according to eq. (12).

\section{Effect of heat transfer fluid-flow rate influence}

Figure 3 shows two infrared images of the 9-elements cast iron radiator obtained at two different water-flow rates: (a) nominal value, $q=q_{n}$, and (b) a quarter of the nominal value, $q=0.25 q_{n}$. From the analysis of such figure, it can be clearly observed that the arithmetic mean temperature is roughly the same for both the cases and for lower water-flow rates a better uniformity of the surface temperature of the radiator is obtained. As regards the measurement uncertainties, on-field uncertainty decreases as the water-flow rate decreases thanks to the increased temperature difference between inlet and outlet sections of the radiator, $\Delta T_{\text {io. }}$.

(a)

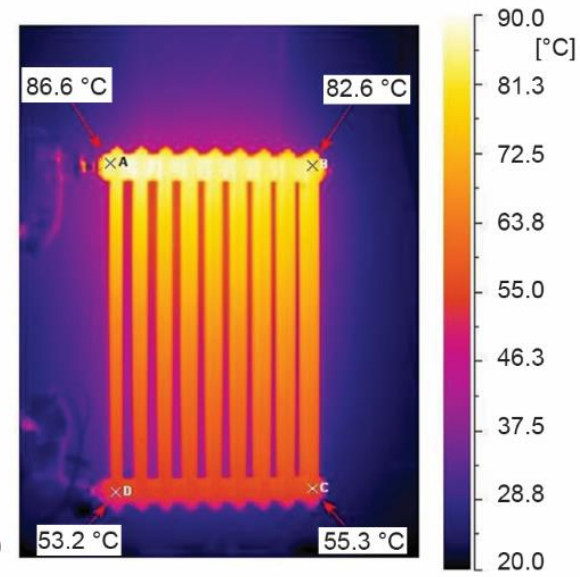

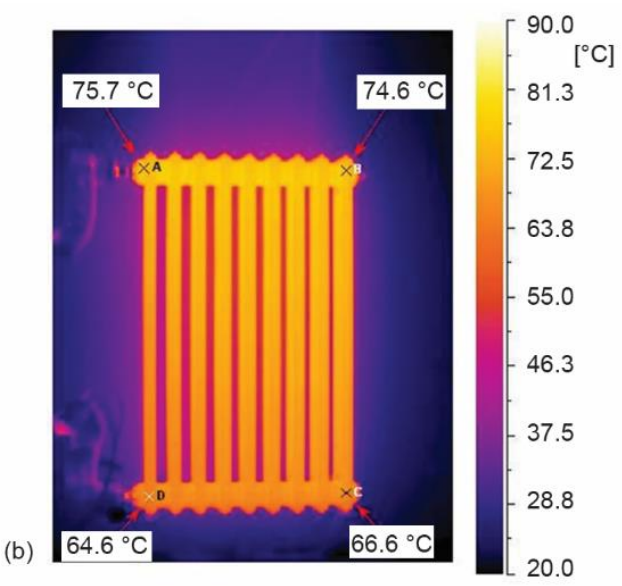

Figure 3. Infrared images of the cast iron heating body obtained for different water-flow rates; (a) water-flow rate equal to nominal value, $q_{n}$, (b) water-flow rate equal to $0.25 q_{n}$ (for color image see journal web site)

Figure 4 shows the thermal output, $\phi$, of the cast iron radiator investigated as a function of heat transfer fluid-flow rate, $q_{m}$, for both EN 442 and on-field measurements. The MRT measurements are available for 3, 6, and 9 elements, while on-field measurements are reported for the 9 -elements case. For water-flow rate higher than about $50 \mathrm{~kg} / \mathrm{h}$ the thermal output slightly increases as the flow rate increases. This is due to the reduced heat transfer fluid temperature drop between the inlet and the outlet sections, $\Delta T_{\mathrm{io}}$, and a consequently almost constant average surface temperature of the radiator. On the contrary, for water-flow rate lower than about $50 \mathrm{~kg} / \mathrm{h}$ the water undergoes a larger inlet-outlet temperature drop. As a conse- 
quence, the radiator mean surface temperature decreases and the thermal output decreases accordingly. It is important to notice that for a lower heat transfer fluid-flow rate larger temperature gradients are evident on the surface of the radiator.

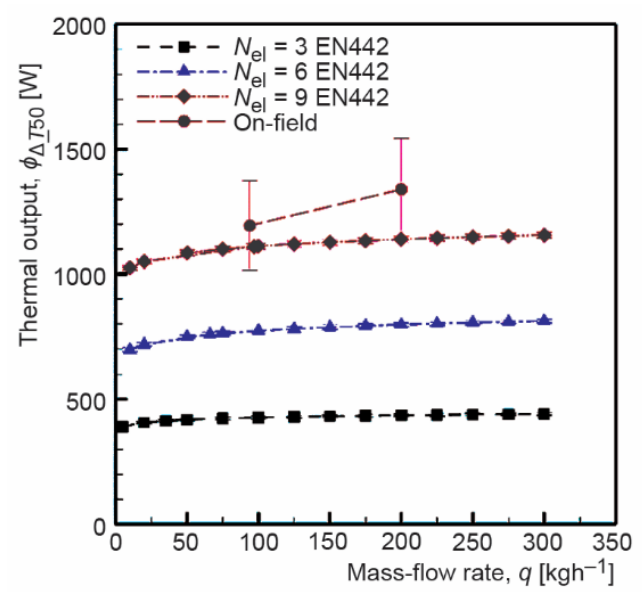

Figure 4. Thermal output as a function of mass-flow rate obtained for cast iron heating body from on field and EN 442 measurements

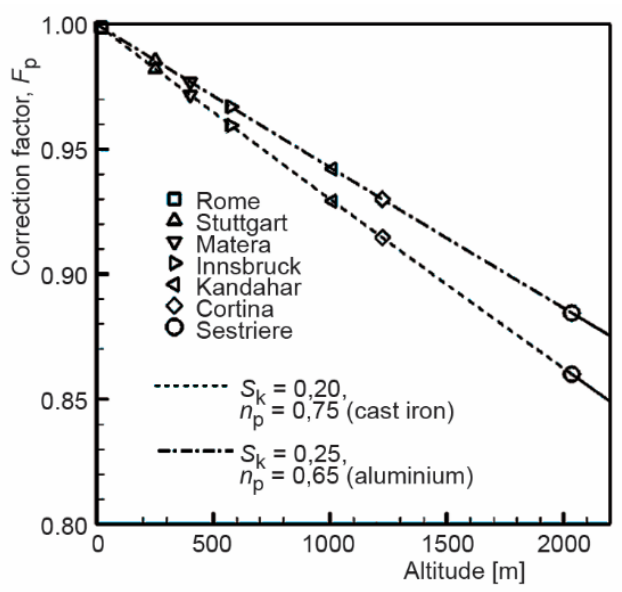

Figure 5. Correction factor, $F_{p}$, as a function of the altitude

\section{Effect of barometric pressure influence}

Figure 5 shows the correction factor, $F_{p}$, as a function of altitude. Assuming an atmospheric pressure of 101325 at the sea level, the barometric pressure variation as a function of altitude is calculated according to the following equation:

$$
p=101325\left(1-2.25577 \times 10^{-5} H\right)^{5.25588}
$$

Seven towns have been taken as an example for the calculation of the correction factor $F_{p}$ according to eq. (10). Rome with an altitude of $20 \mathrm{~m}$ by the sea level, Stuttgart with an altitude of about $250 \mathrm{~m}$, Matera with an altitude of about $400 \mathrm{~m}$, Innsbruck with an altitude of about $575 \mathrm{~m}$, Kandahar with an altitude of $1010 \mathrm{~m}$, Cortina D'Ampezzo whose altitude is equal to about $1225 \mathrm{~m}$, and Sestriere with an altitude of $2035 \mathrm{~m}$ by the sea level.

Correction factor $F_{p}$ ranges from about 0.999 in correspondence of the altitude of Rome to about 0.865 at the altitude of Sestriere. While barometric pressure decrement due to altitude is not expected to significantly affect radiation, it significantly affects convection. In fact, air density decreases as altitude increases heat transfer coefficient decreases accordingly [24], kept constant other parameters.

\section{Analysis of different installation conditions}

In Table 3 the on-field results of the installation conditions influence tests on the actual radiators' thermal output, for both the aluminum and cast iron radiators, are reported. In particular some common installation were analyzed as: shelf, niches, grids, vertical and horizontal positioning, and obstructions due to curtains on the radiator. The major deviation between the actual thermal output and the standard one have been observed in the presence of a grid for both the analyzed radiators. In the case of aluminum radiators, the partial coverage of 
the radiator causes a reduction of the actual thermal output of about $18 \%$ compared to the expected standard value.

Table 3. Influence factors of the installation conditions on the effective thermal output

\begin{tabular}{||c|c|c|c|c|c|c||}
\hline \multirow{3}{*}{ Installation type } & \multicolumn{3}{|c|}{ Cast iron } & \multicolumn{3}{c||}{ Aluminum } \\
\cline { 2 - 7 } & $\begin{array}{c}\text { Wall } \\
\text { distance } \\
{[\mathrm{cm}]}\end{array}$ & $\begin{array}{c}\text { Floor } \\
\text { distance } \\
{[\mathrm{cm}]}\end{array}$ & $\begin{array}{c}\Delta \phi \\
{[\%]}\end{array}$ & $\begin{array}{c}\text { Wall } \\
\text { Distance } \\
{[\mathrm{cm}]}\end{array}$ & $\begin{array}{c}\text { Floor } \\
\text { Distance } \\
{[\mathrm{cm}]}\end{array}$ & $\begin{array}{c}\Delta \phi \\
{[\%]}\end{array}$ \\
\hline Correct installation & 6 & 11 & 0.00 & 2 & 10.5 & 0.00 \\
\hline Shelf & 6 & 11 & 0.47 & 2 & 10.5 & 0.18 \\
\hline Niche & 6 & 11 & -1.83 & 2 & 10.5 & -6.3 \\
\hline Grid & 6 & 11 & -16.2 & 2 & 10.5 & -11 \\
\hline Horizontal position & - & - & - & 16 & 10.5 & -0.5 \\
\hline \multirow{2}{*}{ Vertical position } & 6 & 19 & -0.29 & 16 & 19 & 2.96 \\
\cline { 2 - 7 } & 6 & 26 & 0.24 & 16 & 26.5 & 3.87 \\
\hline Partial obstruction & - & - & - & 16 & 10.5 & -17.7 \\
\hline
\end{tabular}

\section{Analysis of different connections influence}

Table 4. Thermal power variation with the connection mode

\begin{tabular}{|c|c|c|c|c|c|}
\hline \multirow{2}{*}{ Connection } & \multirow{2}{*}{ Scheme } & \multicolumn{2}{|c|}{$\begin{array}{l}\text { High flow rate } \\
\text { (about } 200 \mathrm{~kg} / \mathrm{h} \text { ) }\end{array}$} & \multicolumn{2}{|c|}{$\begin{array}{l}\text { Low flow rate } \\
\text { (about } 70 \mathrm{~kg} / \mathrm{h} \text { ) }\end{array}$} \\
\hline & & $\phi_{\Delta T 60,}[\mathrm{~W}]$ & $\Delta \phi,[\%]$ & $\phi_{\Delta T 60,[\mathrm{~W}]}$ & $\begin{array}{l}\Delta \phi, \\
{[\%]}\end{array}$ \\
\hline A (mixed flow) & & 1779 & 0.0 & 1770 & -0.5 \\
\hline B (counter-current flow) & & & & 1761 & -1.0 \\
\hline $\mathrm{C}$ (crossflow) & & 1701 & -4.4 & 1552 & -12.8 \\
\hline $\begin{array}{l}\text { D (single pipe with short } \\
\text { stemmed valve) }\end{array}$ & & 1527 & -14.2 & & \\
\hline $\begin{array}{l}\text { E (single pipe with medium } \\
\text { stemmed valve) }\end{array}$ & & & & 1440 & -19.1 \\
\hline $\begin{array}{l}\text { F (single pipe with long } \\
\text { stemmed valve and nozzles) }\end{array}$ & & 1628 & -8.5 & 1388 & -22.0 \\
\hline $\begin{array}{l}\mathrm{G} \text { (single pipe with long } \\
\text { stemmed valve and separator) }\end{array}$ & & 1727 & -2.9 & 1547 & -13.0 \\
\hline
\end{tabular}


In tab. 4 the on-field results of the connections influence test on the actual radiators' thermal output are reported at high and low flow rates. In particular, the most common connections were analyzed, such as: mixed flow (inlet left high/outlet right low), counter-current flow (inlet left high/ outlet left low), cross-flow (inlet left low/outlet right low), single pipe with short stemmed valve, single pipe with medium stemmed valve, single pipe with long stemmed valve and nozzles, and single pipe with long stemmed valve and separator. The higher deviations between the actual thermal output and the standard one were observed with single pipe valve at low flow rate. In such conditions the deviations of thermal output in respect to the reference optimal configuration can be higher than $20 \%$.

\section{Conclusion}

On the basis of measurements, it can be evidenced that radiators thermal output strongly depends on typology and shape, operating conditions (average temperature, waterflow rate, pressure) and installation (number of elements, installation position, connection type, presence of grids, shelf, niches, or obstructions). The adoption of thermostatic valves and the improvement of building envelope and windows insulating performance determines a reduction of required thermal output from radiators. As a consequence, radiators operate at lower temperatures thus resulting in an improved heating plant efficiency, but such operating condition is not taken into account by international standards for heat cost allocators according to EN 834, that refer to $\Delta T=60 \mathrm{~K}$. The only exception is represented by the mean temperature difference between the heat transfer fluid and the environment, even though such temperature is sometimes not measured and the definition of the reference position is not a simple issue. As a consequence, required overall plant heating output can result underestimated and heat cost allocation for space heating can be inaccurate and unfair. In particular, major issues are associated to: connection type adopted, that determines reduction of the radiators' thermal output up to about $15 \%$ (in the case of single pipe short-stemmed valve) and between $10 \%$ and $20 \%$ for flow rates of $30 \%$ of the standard flow rate and non-conventional connections (mixed flow or counter-flow), and installation conditions that evidence a difference between operating and standard thermal output between $5 \%$ and $15 \%$. It is evident that the designer can take into account the above described aspects to correct the standard thermal output declared by the manufacturer in accordance to EN 442. In fact indirect heat accounting according to EN 834 and the UNI 10200 prescribe the adoption of the standard thermal output without any correction. As a consequence, since standard and operating conditions could be significant different, not negligible errors in space heating cost sharing can occur.

\section{Acknowledgments}

The present work has been realized within the project PRIN Riqualificazione del parco edilizio esistente in ottica NZEB (nearly Zero Energy Buildings).

\section{References}

[1] ***, Directive 201227/EU, 25 October 2012

[2] Celenza, L., et al., Heat Accounting in Historical Buildings, Energy and Buildings, 95 (2015), May, pp. 47-56

[3] Ferrero, A., Marchesi, R., The Fundamentals of the Measurement Technique, NATO Handbook of Measurements, NATO, Washington DC, 2002, pp. 9-17

[4] Arpino, F., et al., Influence of Installation Conditions on Heating Bodies Thermal Output: Preliminary Experimental Results, Energy Procedia, 101 (2016), Nov., pp. 74-80

[5] Peach, S., Radiators and other Convectors, J. Inst. Heating Ventil. Eng., 39 (1972), 2, pp. 239-253 
[6] ***, EN 442-1, Radiators and Convectors - Part 1: Technical Specification and Requirements, 2014

[7] ***, EN 442-2, Radiators and Convectors - Part 2: Test Methods and Rating, 2014

[8] ***, UNI 10200, Impianti Termici Centralizzati di climatizzazione invernale e produzione di acqua calda sanitaria - Criteri di ripartizione delle spese di climatizzazione invernale ed acqua calda sanitaria (in Italian), 2013

[9] Brady, L., et al., An Investigation into the Effect of Decorative Covers on the Heat Output from LPHW Radiators, Energy Build., 133 (2016), Dec., pp. 414-422

[10] Embaye, M., et al., Numerical Evaluation of Indoor Thermal Comfort and Energy Saving by Operating the Heating Panel Radiator at Different Flow Strategies, Energy and Buildings, 121 (2016), Jun., pp. 298-308

[11] Calisir, T., et al., Experimental Investigation of Panel Radiator Heat Output Enhancement for Efficient Thermal Use Under Actual Operating Conditions, EPJ Web of Conferences, 92 (2015), May, 02010

[12] ***, EN 834, Heat Cost Allocators for the Determination of the Consumption of Room Heating Radiators, Appliances with Electrical Energy Supply, 2013

[13] Beck, S. M. B., et al., A Novel Design for Panel Radiators, Applied Thermal Engineering, 24 (2004), 8-9, pp. 1291-1300

[14] Ward BSc, I. C., Domestic Radiators: Performance at Lower Mass Flow Rates and Lower Temperature Differentials than those Specified in Standard Performance Tests, Building Serv. Eng. Res. Technol., 12 (1991), 3, pp. 87-94

[15] Marchesi, R., The Thermostatic Room According European Standards, La Termotecnica, 2 (1998), pp. 75-89

[16] Marchesi, R., Calibration of Test Systems for Determining the Thermal Output of Radiators and Convectors, SMT4 CT96-2127 Final Report, Brussels, 1999

[17] Marchesi, R., et al., Test Room Specifications on the Basis of the Research Program, Dipartimento di Energetica del Politecnico di Milano, CEN TC-130, No. 45, Report of the W.G. 4, 1989

[18] Celenza, L., et al., Economic and Technical Feasibility of Metering and Sub-Metering Systems for Heat Accounting, International Journal of Energy Economics and Policy, 6 (2016), 3, pp. 581-587

[19] Ficco, G., et al., Experimental Comparison of Residential Heat Accounting Systems at Critical Conditions, Energy and Buildings, 130 (2016), Oct., pp. 477-487

[20] ***, EN 1434-1, Heat Meters - Part 1: general requirements, 2015

[21] Coleman, H. W., Steele, W. G., Experimentation and Uncertainty Analysis for Engineers, $2^{\text {nd }}$ ed., Wiley, New York, USA, 1999

[22] Betta, G., et al., Experimental Design Techniques for Optimising Measurement Chain Calibration, Measurement: Journal of the International Measurement Confederation, 30 (2001), 2, pp. 115-127

[23] Dell'Isola, M., et al., A Novel Model for the Evaluation of Heat Accounting Systems Reliability in Residential Buildings, Energy and Buildings, 150 (2017), Sep., pp. 281-293

[24] Saidi, M., Abardeh, R. H., Air Pressure Dependence of Natural-Convection Heat Transfer, Proceedings, Worlds Congress on Engineering WCE2010, London, UK, 2010 